\title{
Humanistic Management: What Has Love Got to Do with it?
}

\author{
Michael Pirson ${ }^{1} \cdot$ Cinzia Dessi $^{2} \cdot$ Michela Floris $^{2} \cdot$ Ernestina Giudici $^{2}$ \\ Published online: 28 April 2021 \\ (C) The Author(s), under exclusive licence to Springer Nature Switzerland AG 2021
}

As the COVID Pandemic has shocked and transformed our societies and organizations we are at a crossroads in terms of what can arise? Shall we build back what was before or build back better. How would we build back better? What seems to be clear is that perennial human needs that cannot be ignored. Being a fundamentally social being is one of those truths that the pandemic with its lockdowns and social distancing is shining light on.

In management we have long witnessed the pandemic of psychopathic individualism and the ensuing estrangement of people and their organizations. Employee engagement and stakeholder trust are persistently low and arguably influenced by a corporatist approach to organizing. Family businesses often do have a competitive and collaborative advantage as they provide a higher sense of purpose and community to many people.

Love is a way to understand what distinguishes what family businesses are doing from what more conventional businesses are doing. Bob Chapman, CEO of the manufacturing conglomerate Barry-Wehmiller, argues that dignity and love are powerful leadership ingredients lost in traditional approaches to business management.

In this issue we create space for the topics of love, dignity and the common good in the frame of family firms and beyond. In a first contribution Luigino Bruni (Bruni, 2021) examines the notion of managerial reason. He argues that the current corporation has cultural power in that it shapes the narrative of virtues in business and beyond: politics, education, health care and beyond. We talk about notions of merit, efficiency, competition, leadership, incentives and innovation when discussing communal life. In reassessing the value of the community as an organizing mechanism- as distinct from hierarchy and market- he elaborates on virtues including love that despite their current irrelevance are becoming more and more crucial for the survival and growth of organizations.

In a second contribution Roberta Sferrazzo (Sferrazzo, 2021) argues similarly that current corporate systems concentrate only on economic results by favoring, through the incentive and award system, only what can be seen, produced, and measured. As such, these systems are

Michael Pirson

pirson@fordham.edu

1 Fordham University, The Bronx, NY, USA

2 Universita di Cagliari, Catania, Italy 
unable to recognize workers' agapic behaviors -similar to the ones considered in organizational citizenship behavior (OCB) literature- that cannot be quantified, i.e. workers' generosity, humanity, kindness, compassion, help for others and mercy. Although these types of behaviors may appear unproductive or irrational, they create symbols of belonging to the company and social cohesion. Her article claims that beyond focusing on reward systems, companies should recognize agapic behaviors to increase workers' intrinsic motivation. These behavioral attitudes allow fraternal relationships -as conceived in the Civil Economy tradition- to arise within organizations; moreover, they contribute to advancing new managerial practical implications in the humanistic management field.

We have compiled a special section on family businesses and their role in a more humane economy. Cinzia Dessi and Michela Floris together with Ernestina Giudici managed this process. The articles here are extending the above perspectives on love and organizing through the lens of the family based business enterprise.

In a third contribution, Dov Fischer and Hershey Friedman (Fischer \& Friedman, 2021) examine the idea of love in organizations through the lens of \#Metoo. Using a biblical story from the Book of Ruth, the authors illuminates how family firms can honor human dignity in the context of sexual harassment. They also highlight the tension that such paternalistic structures lead to power imbalances that undermine dignity. Creating a values based culture using stories and enabling managerial risk taking is one of the core challenges they point out.

In a fourth contribution, Giorgia Nigri and Riccardo Di Stefano (Nigri \& Di Stefano, 2021) analyze the family business as an organizational entity and as a proprietary form with the objective of transmission of personal values and company assets to the next generation. The author assesses legal instruments in Italy for transmission of family businesses between generations, including the trust and the family pact, and to evaluate how these are useful for ensuring not only the survival of the company in the market but also that family values and characteristics pass from one generation to the next under a humanistic management perspective.

In a fifth contribution María-Asunción Esteso-Blasco, María Gil-Marqués and Juan Sapena (Esteso-Blasco et al., 2021) examine organizations within the tradition of "Economy of Communion (EoC)." Their research aims to understand how Economy of Communion (EoC) companies respond to global and competitive challenges by applying the logic of gratuitousness and giving. The paper examines the altruistic behaviour of EoC leaders and the connection with organizational innovation, necessary for firm's survival in the long-term. The findings reveals that innovation derives from the desire to help others, such as employees and customers. Moreover, the findings reveal that a culture of dialogue among employees, managers and the whole organisation enhances risk-taking and, therefore, innovation. As a result the paper enhances our understanding of how EoC companies are able to reconcile innovation with the ideal of altruism.

Concluding the special section Mark Ryan (Ryan, 2021) examines the company Patagonia through a humanistic management lens. In his essay the authors claims that the task for those with philosophical training is to avoid unintentionally widening the gap between philosophical theory and those engaged in business management by emphasizing the centrality of practical wisdom (phronesis) to the moral life. Drawing on the concepts of social practice and of narrative he ties practical reasoning to the story of the company Patagonia. Practical reason, social practices and narrative are employed together to give an account of the art of management at Patagonia. With his essay Ryan hopes to both provide a way for philosophers to 
harmonize their practice with that of management and a narrative contribution to the literature of Humanistic Management.

In a separate piece, the Ronald Ferguson, Kaspar Schattke, and Michele Paulin (Ferguson et al., 2021) present research guided by the important need for a diversion from an economistic to a humanistic management perspective of sustainability. It concentrates on the current importance of digital strategic communication, particularly regarding the concept of corporate sustainability in the context of the conflict arena of the oil industry. The focus is on the comparison of the persuasive effectiveness of the messages of corporate versus activist NGO website strategic communications and their impacts on the perception of the triple pillars of sustainability and, corporate greenwashing with respect to the proposed Energy East bituminous oil pipeline in Canada. The results of these pro and con messages were analyzed within the Elaboration Likelihood Model demonstrating a "non expert" peripheral route to a positive persuasion from exposure to the corporate communication versus an "expert" central route to a negative persuasion from the activist NGO communication. Subsequent exposure to the opposite website communication further emphasized the predominance of a negative persuasion based on both groups now being motivated as "expert" viewers of these strategic communications, leading to an important perception of greenwashing resulting from vague claims, visual and linguistic contents of the corporate communication versus the mainly verifiable factual ones in that of the Activist NGO.

In a final essay Julia Kasmire (Kasmire, 2021) presents her thinking about balance as a central objective within the sustainable business discourse. Although sustainability may appear to be a thoroughly twenty-first century goal, sustainability science concepts and goals such as balance, endurance, order and change, reach back at least as far as the protoscientific investigations of alchemy. Both alchemy and sustainability science can be understood as systems or strategies which individuals and societies can use to organise and manage themselves in a complex world filled with dynamic problems. Alchemy never created a panacea or transmuted base metals into gold because those goals proved to be based on fundamentally flawed theories and premises. Nevertheless, alchemy did succeed in helping adherents manage themselves and their societies in advantageous ways. Alchemy also positively and significantly influenced subsequent scientific development. Likewise, science helps humanity manage itself on multiple scales, from the individual to the international, and will certainly contribute to further scientific research and development. However, it is not yet known whether carbon neutrality, entirely renewable energy and other sustainability goals will be achieved or whether these goals will also come to be seen as based on flawed understandings and theories. For this reason, this article explores key features of alchemy, traces how they persisted through Enlightenment-era science and how they continue to be present and influential within scientific efforts today. The article goes on to reflect on how the history, development and continued use of concepts such as balance, endurance, order and change may be useful portents of how humans and human society will manage themselves in the future. Such reflections may also temper the zeal with which individuals that accept or reject sustainability goals treat each other, thereby offering a way for divergent groups to manage their interactions.

\section{References}

Bruni, L. 2021. Critique of managerial reason. Humanistics Management Journal 6 (1): 5-18. 
Esteso-Blasco, M.A., M. Gil-Marqués, and J. Sapena. 2021. Leadership in economy of communion companies. Contribution to the common good through innovation. Humanistics Management Journal 6 (1): 77-101.

Ferguson, J., K. Schattke, and M. Paulin. 2021. Persuasions by corporate and activist NGO strategic website communications: Impacts on perceptions of sustainability messages and greenwashing. Humanistics Management Journal 6 (1): 117-131.

Fischer, D., and H. Friedman. 2021. Family business in the \#MeToo era: Lessons from Ruth on tone at the top. Humanistics Management Journal 6 (1): 37-55.

Kasmire, J. 2021. Managing balance: Pursuit of equilibrium permeates the history of science and influences contemporary investigations. Humanistics Management Journal 6 (1): 133-146.

Nigri, G., and R. Di Stefano. 2021. Family business in Italy: A humanistic transition of assets and values from one generation to the next. Humanistics Management Journal 6 (1): 57-76.

Ryan, M.R. 2021. Business ethics as a form of practical reasoning: What philosophers can learn from Patagonia. Humanistics Management Journal 6 (1): 103-116.

Sferrazzo, R. 2021. The 'Agapic behaviors': Reconciling organizational citizenship behavior with the reward system. Humanistics Management Journal 6 (1): 19-35.

Publisher's Note Springer Nature remains neutral with regard to jurisdictional claims in published maps and institutional affiliations. 